\title{
INMIGRACIÓN LATINOAMERICANA EN PARÍS. ESTRATEGIAS DE INTEGRACIÓN Y REDES DE SOCIALIZACIÓN
}

\author{
ISABEL SANTI
}

Université París 8 (France).

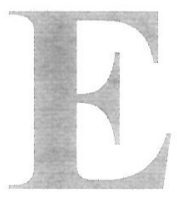

\section{RESUMEN}

ste artículo propone un estudio de la circulación de los latinoamericanos en el espacio de la Unión Europea. A través de los nuevos procesos migratorios, analizaremos estrategias sociales y re-negociaciones identitarias centrando nuestro trabajo en el caso de los latinoamericanos en París, considerando esta ciudad de recepción como "escala" del periplo migratorio. En una conclusión provisional evocaremos las repercusiones reales o no de los procesos migratorios actuales en la construcción identitaria del migrante.

Palabras clave: Inmigración, Francia, integración, redes, identidad.

Francia es un país con una larga historia de inmigración que adquiere diferentes aspectos, con gran diversidad de proveniencias y va adaptando sus políticas migratorias según los flujos migratorios y las épocas.

Actualmente, a la multiplicidad de orígenes de los inmigrantes y la diversidad de situaciones de los mismos se ha ido superponiendo una "globalización" de circunstancias y de movilidad migrante a la que las autoridades y la sociedad enfrentan con actitudes evolutivas dentro del marco simbólico de integración republicana; mientras que los migrantes van explorando estrategias posibles.

Presentaremos en este trabajo algunas reflexiones preliminares sobre un estudio de terreno en curso referido a la migración latinoamericana actual, en la ciudad de París. Realizamos entrevistas en marzo y abril de 2004, ciñendo el terreno a una estructura de socialización pre-existente, cual es la Misión Española de París, que se encuentra en el distrito 16, barrio Parísino de clase media alta. 
Comenzaremos exponiendo algunas consideraciones sobre la sociedad de recepción francesa y sobre los conceptos que se manejan, en los estudios migratorios, en términos de integración, socialización e identidad.

El historiador Patrick Weill señala que, en Francia, las políticas específicas que se aplican a la situación social del extranjero residente abarcan cuatro sectores principales: alojamiento, educación, empleo y derechos: derechos civiles, de residencia, de asociación, de práctica de la religión elegida y derecho a la identidad cultural. Estas políticas, añade, nunca fueron ni prioritarias ni coherentes en Francia. Fueron dependientes de la política de los flujos migratorios $\mathrm{y}$, por ende, de la respuesta, variable, a la pregunta siguiente: $¿$ Qué se quiere hacer con los inmigrantes? Pero también dependen, las políticas, de las grandes administraciones del Estado, con sus propias lógicas de intervención. Además, no sólo estas políticas enfrentan a la administración oficial con los inmigrados residentes, sino también al inmigrante con otros actores sociales o políticos: empresas, colectividades locales, docentes, asociaciones y entidades religiosas de beneficencia que no son influenciables por responsables nacionales.

La sociedad francesa, como muchas sociedades contemporáneas, se caracteriza por la multiplicidad creciente de grupos de pertenencia reales o simbólicos a las que adhieren los individuos. En un primer círculo se distinguen los grupos primarios de pertenencia, familia, profesionales, amigos. El segundo círculo lo constituyen las instituciones culturales, religiosas o políticas. Por último, en Francia, gran parte de la construcción identitaria se lleva a cabo en la relación, conflictiva o no, con la instancia social y política por excelencia desde hace varios siglos, que se inscribe en la tradición republicana asimiladora, es decir, el estado-nación. Sin duda, empieza a emerger, a partir de inquietudes morales, ecológicas e igualitarias una identificación más global representada por la humanidad-mundo.

Las estrategias identitarias del inmigrante, en esta sociedad de recepción, actúan a través de sus conductas en las relaciones interculturales; la identidad no aparece como la simple yuxtaposición de actuaciones y pertenencias sociales, sino que debe apreciarse como un todo dinámico, del que resultan las estrategias a través de las cuales el inmigrante, como individuo, tiende a defender su existencia y visibilidad social, su integración en la comunidad predominante al tiempo que se valoriza buscando su propia coherencia. Añadamos que en la sociedad de acogida, el inmigrante, al enfrentar nuevas situaciones de socialización, cuestiona su propia identidad. Efectivamente, la socialización se define (G. Vinsonneau, 2002) como las modificaciones que se producen en 
esa oportunidad en las relaciones de cada uno con su entorno y consigo mismo, paralelamente, el inmigrante re-construye su identidad en la relación de adhesión o de rechazo que va estableciendo en sus grupos de contacto. Se posibilitan múltiples identidades sociales: pueden elegirse agrupaciones asociativas, el grado de integración y pertenencia podrá variar, pero las prácticas son similares y los procesos de identificación comunes aunque cada identificación sea específica, marcada por la historia, la existencia o no de comunidades de referencia; la novedad, en lo que observamos son las identidades "chapuceadas" ("bricolées"), oportunas, con cantidad de pertenencias frágiles o fuertes.

En lo que se refiere a la integración (D. Schnapper, 1990), ésta se produce según tradiciones específicas de cada nación y acarrea para los migrantes un cuestionamiento de identidades y de culturas. En los procesos de integración pasados, el mantenimiento de la cultura de origen en el ámbito privado fue compensado por el sentimiento de pertenencia a una entidad que le aportaba al individuo algo que era percibido como superior. Sólo se logra la integración si la comunidad de recepción ofrece algo que la valorice.

Lo que subsiste de la lógica republicana francesa, mas allá de las ambigüedades ideológicas que nutren los debates públicos, entre multiculturalistas e integracionistas (M. Wieviorka, D. Schnapper 1990, 1996), es la voluntad de otorgar la igualdad de derechos en función de situaciones individuales realmente semejantes. Acaso se cuestione esta logica, a su tiempo y sazón, con la construcción europea y se admita que la inmigración no es una totalidad homogénea, al elaborar un "contrato de ciudadanía europeo".

En el contexto francés actual, el discurso oficial menciona la cantidad de cien mil inmigrantes legalizados por año, de una política de inmigración asumida y responsable, de un proyecto de integración renovada, de reformar el derecho de asilo agilizando las gestiones y de reorganizar la política de retorno. Se insiste en que la responsabilidad consiste en reconocer que es imposible recibir a todos los que lo deseen. Además, el "nuevo migrante" deberá adherir a los valores republicanos a través de una jornada de información obligatoria y de doscientas horas de clases de francés (discurso del primer ministro ante la Asamblea Nacional, 14 de junio 2004). La integración deberá relacionarse al tema de cohesión social e incluso al tema identitario francés. Se cobra conciencia de que los flujos migratorios evolucionan y se organizan a nivel planetario y que ya no bastan respuestas nacionales, imponiéndose una concertación europea. 
La inmigración latinoamericana reciente es, en Francia, relativamente poco numerosa comparada con otros flujos migrantes extra-comunitarios y su "visibilidad" social es deleznable, baste con comparar, en ese sentido a ciudades como París con Madrid o Barcelona. Sin embargo, siempre hubo inmigración latinoamericana en Francia; según datos de la Prefectura de París, es cíclica, por oleadas, varía según las situaciones de algunos países. Pueden evocarse, esquematizando y, por épocas: la emigración de los años 1950 y 1960, a nivel de visibilidad, por ser una emigración de intelectuales y exiliados de las primeras dictaduras que fueron abriendo el camino para la migración del exilio político de los años 70, que fue la más "visible" socialmente, por el hecho de que, entonces, muchos exiliados se incorporaron a instituciones como la universidad que proporciona más posibilidades de ascenso social a organismos oficiales de prestigio como algunos ministerios o administraciones municipales, beneficiando de una coyuntura política favorable. En los años 80 y 90, llegan colombianos y peruanos, refugiados políticos y migrantes económicos; se constituyen redes por regiones, se organizan en algunos barrios de los suburbios Parísinos pero su "visibilidad" social es marginal y numerosos gestionan la residencia y la naturalización.

En la actualidad, tanto los datos, aproximativos, del Ministerio del Interior como los de la Prefectura de París, demuestran que varían entre treinta mil o más, mucho más por el hecho de estar la mayoría en condición de ilegalidad o en trámite; numerosos son "retornados" por los servicios policiales, otros están encarcelados.

En nuestro estudio de terreno, estimamos que un promedio de entre cincuenta y ochenta latinoamericanos migrantes ilegales por semana acuden a pedir ayuda a la Misión Española de París. Esta Iglesia constituye un enclave español en un barrio Parísino; fue comprada en 1914 por el rey de España, Alfonso XIII, para brindar servicio religioso a los trabajadores españoles que llegaban para reemplazar a los franceses que combatían en la primera guerra mundial. Estos migrantes laborales no hablaban francés, ni tenían proyectado instalarse. Habiéndose, por ley de 1905, separado la Iglesia del Estado en Francia, estos españoles corrían el riesgo de abandonar la religión. Se confió esta parroquia a los misioneros claretianos españoles que debían cumplir una misión pastoral, saliendo en búsqueda del migrante. Muchos de los que llegaron solos terminaron trayendo a sus familias e instalándose. En los años 60 , la iglesia estaba llena los días de culto y se llegaron a celebrar hasta mil quinientos bautismos y matrimonios al año.

Actualmente, la iglesia se llama Iglesia Hispanófona y la frecuentan principalmente los migrantes latinoamericanos, aprovechando una 
estructura pre-existente cuya mayor ventaja inicial, para ellos, es la de poder ser allí, entendidos en español. Cuenta con cinco misioneros españoles y costarricenses y la misión pastoral se ha extendido a una acción de ayuda social multifacética.

Contrariamente a épocas anteriores, los misioneros no conocen bien los problemas de los nuevos inmigrantes ya que no salen en busca de nuevos feligreses sino que esperan en el local de la parroquia, donde han puesto a disposición de los latinoamericanos una oficina permanente de ayuda social y laboral, una permanencia de ayuda jurídica atendida por abogados benévolos, para tramites de legalización y un ropero.

El trabajo de campo se realizó llevando a cabo entrevistas entre los migrantes que acuden los días de permanencia, que se realizan los mismos días de la semana, con lo cual el migrante puede consultar en las tres oficinas. A nivel metodológico, no se utilizaron cuestionarios elaborados previamente estimando que las aportaciones narrativas construidas libremente por el entrevistado sobre la experiencia vivida, evita el sugerirles cómo deben considerar su experiencia, y nos permite apreciar el aporte del espacio interrelacional de la iglesia hispanófona.

Según el sacerdote responsable de la parroquia, a nivel de nacionalidades, los migrantes llegan por "rachas". Casi todos los que hemos entrevistado no llevaban más de un año en París, la mayoría eran bolivianos, la ultima "racha" (según el sacerdote responsable) y ecuatorianos, si bien él considera que los más numerosos, pero de más antigua presencia en el país sean los colombianos y bolivianos.

De una primera exploración, extraemos las observaciones siguientes.

En todo proceso de integración, independientemente del modelo de la sociedad, interviene la re-elaboración de la identidad nacional del migrante. En esta primera fase, los espacios de socializacion religiosa, de alguna manera aportan un apoyo a nivel emocional, un entrenamiento a la adaptación voluntarista a nuevos códigos y la asimilación de roles que le permitan interpretar bien las situaciones que irán atravesando para evaluar con qué identidad social va a ir negociando su supervivencia. Ver si le conviene o no re-elaborar su sensación de identidad étnica contextualizando su experiencia de las marcas étnicas que la distinguen. Máxime cuando en la iglesia hispanófona encuentran una estructura de socializacion que no emana de, ni representa a la sociedad de recepción, siendo, supuestamente, para ellos un ambito confiable, el migrante que rehace su identidad étnico-social, lo hace con referencia a la de otros de su mismo país y condición, lo que les permite los encuentros con otros 
migrantes que están recorriendo el mismo itinerario. Un joven ecuatoriano entrevistado:

[...]"Tuve que llenar muchos formularios para ver si me admiten a un instituto de informática, como hacen unos amigos colombianos, y como soy de Guayaquil, puse que era de nacionalidad colombiana, porque a ellos les fue bien, por eso de los convenios bilaterales (entre Francia y Colombia) y asi tienen seguro social y muchas ventajas más..."

Aparece frecuentemente, en el discurso de los entrevistados, el carácter de "agencia de empleo" que atribuyen a la institución religiosa, puesto que el contacto y espacios de reunión que allí encuentran, se convierte en redes de información laboral, posibilidades de trabajo formal o no, recomendaciones de monjas y sacerdotes que cuentan para el empleo en servicio doméstico que brindan las inmediaciones barriales; todos estos elementos concretizan una apreciable función de red social.

A diferencia de otras religiones representadas en París, la católica ya no constituye el carácter diferenciador de identidad de antaño y ha dejado de dar una ubicación de pertenencia a un grupo de influencia valiosa, aunque siga siendo una ventaja contar con su recomendación en un barrio de clase alta en París.

Las relaciones con el inmigrante adquieren un carácter más burocratizado, aunque eficaz, por encontrar agentes mediadores en el ambito parroquial. Pero, ante todo, en el caso de la iglesia hispanófona, hallan los migrantes una interdependencia importante, que facilita el "estar con otros" encontrando un espacio de pertenencia ficticio, basado sólo en el "poder hablar español":

“... Si vengo a misa el domingo es para oír hablar español, aunque no conozca a nadie ni sepa rezar como ellos, es pasar el rato, como en la iglesia grande de Santa Cruz...", dice una señora boliviana que trabaja en una familia francesa del barrio toda la semana.

El "estar juntos", ya no tanto con compatriotas, sino con latinoamericanos es la razón más frecuentemente evocada por los entrevistados refiriéndose al vínculo con la iglesia hispanófona. Esta razón es interesante, sumada a otra, mencionada por los ecuatorianos que llegan, provenientes de España y señalan la ventaja que constituye, en Francia, el no ser inmediatamente reconocible como latinoamericano:

“... Llevo tres meses buscando trabajo, por fin encontré algo provisorio como reemplazante de cuidador de parking por la noche, estoy reemplazando a un indio de la India que creyó que yo también era de su pueblo, por lo menos aqui nadie me trató de "sudaca" todavia...", un joven ecuatoriano. 
Lo que es considerado como "ventaja", por suprimir un estigma singular, implica que, al diluirse entre la masiva cantidad constituida por inmigrantes, mano de obra no cualificada, el ecuatoriano, boliviano, colombiano o peruano que se ha sentido estigmatizado por ser latinoamericano, en París es un inmigrante excluido social más, lo protege contra el estigma el anonimato.

En realidad, el acudir a la iglesia católica, era práctica usual en los países de los entrevistados y, en París, esa posibilidad es la continuación de una costumbre; les resulta más fácil que dirigirse a organismos oficiales, encuentran allí un amago de cohesión social. La mayoría de los que sólo llevan algunos meses en París no tiene planes definidos más allá de resolver la situación inmediata, dejando para después del vencimiento de la visa de turista, la búsqueda de algo mejor, aunque sea en otro país comunitario. Muchos mencionan Alemania, Inglaterra o Suecia, aunque se crucen en el trayecto con otros migrantes provenientes de Países Bajos y Alemania que imaginan mejor suerte en Francia y España o Italia.

"... Soy boliviano, de Escobar, tengo primos de Cochabamba y otros amigos que conocí en España que me dijeron que después de Paris es bueno irse para Alemania o Inglaterra, hay buena plata alli, para ir juntando y mandar..." dice un señor boliviano, ya pensando en irse; llama la atención que mencione Escobar sin precisar que esa localidad se encuentra en la provincia de Buenos Aires, destacando la movilidad como característica interiorizada entre los actores de esta nueva migración.

\section{A MODO DE CONCLUSIÓN}

En el periodo considerado los inmigrantes entrevistados eran mayormente bolivianos y ecuatorianos, recientemente llegados a París.

En términos de estrategias de integración y redes de socialización, el espacio que ofrece la Iglesia Hispanófona de París configura actualmente un enlace entre etapas migratorias. Resulta patente, por ejemplo, la falta de proyecto migratorio definido de migrantes que están "de paso", la mayoría de ellos no llega directamente a Francia y no está segura de querer instalarse; la integración se convierte en sinónimo de subsistir día a día.

Las redes de socialización que se establecen son precarias y cambiantes; si bien la inmigración actual está en aumento, se caracteriza por la dispersión y la movilidad de los migrantes, reduciendo su visibilidad social real como latinoamericano. De hecho, la prensa francesa 
que abunda en artículos sobre la inmigración bajo múltiples aspectos, casi nunca menciona a migrantes latinoamericanos.

Las adaptaciones y re-elaboraciones identitarias ya no están determinadas unilateralmente por la sociedad de recepción, si tenemos en cuenta la capacidad generalizada de contacto permanente con la sociedad de origen y las de la última y próxima etapa. Las identidades chapuceadas ("bricolées") se van configurando según las oportunidades de supervivencia y mejoramiento de las condiciones diarias, ya no se trata de ascenso social.

N. Canclini estima que "la construcción y re-adaptación incesante de las identidades son fruto de la globalización y, a pesar de una historia compartida, lo latinoamericano no es una esencia. Más que una identidad, es una tarea."

\section{BIBLIOGRAFÍA}

BOURDIEU, P. et al. La misère du monde, París, Ed. Du Seuil. (1993).

CANCLINI, N. Latinoamericanos buscando lugar en este siglo, México, Ed. Paidos (2002).

NOIRIEL, G. Histoire de l'immigration en France. París, Ed. Belin (1988).

SCHNAPPER, D. La citoyenneté. París, Ed. Du Seuil (1990).

SAYAD, A. La double appartenance. París, Ed. Du Seuil (1995).

VINSONNEAU, G. L'Identité culturelle. Paris, Ed. A. Colin (2001).

WEIL, P. La France et ses étrangers. París, Ed. Calmann Levy (1991).

WIEVIORKA, M. Une société fragmentée. París, Ed. La Découverte, (1996).

WIMLICKA, P. La citoyenneté multiculturelle. Bruxelles, Ed. Complexes (1995).

WITHOLD DE WENDELL, C. Les immigrants et la politique. París, Presses de Sciences Politiques (1988). 